\title{
Development of organosilicon decorative coating with craquelure effect
}

\author{
(C) Alexander A. Kirillov, Sergey P. Mikheev, Mikhail V. Kuzmin, and Nikolay I. Koltsov** \\ Department of Physical Chemistry and Macromolecular Compounds. Chuvash State University \\ of I.N. Ulyanov. Moskovsky Ave., 15. Cheboksary, 428015. Chuvash Republic. Russia. \\ Phone: +7 (8352) 45-24-68. E-mail: koltsovni@mail.ru
}

\begin{abstract}
*Supervising author; ${ }^{+}$Corresponding author Keywords: organosilicon compositions, modification, physical-mechanical and decorative properties, termo resistance, coating, craquelure effect.
\end{abstract}

\begin{abstract}
The article analyzes coatings based on organosilicon compounds and presents the results of research on the selection components of compositions that provide protection of painted products from corrosive environments, mechanical and thermal effects. Defects of paint and varnish coatings are investigated. The expediency of modifying organosilicon film-forming compositions with solutions bead polymers of polymethyl methacrylate and polybutyl methacrylate has been substantiated. To obtain a heat-resistant coating, two compositions were developed for the lower and upper layers. The bottom layer was KO-85 organosilicon varnish modified with solutions of bead polymers and PF-060 alkyd varnish. To regulate the wetting and spreading, surfactants were introduced into the bottom layer, which could improve the structural, mechanical and decorative properties of the coatings. The top layer of the coating with the craquelure effect was KO-868 silicone enamel modified with functional additives that increase the surface tension and reduce the spreadability of the resulting composition. Research has been carried out on the physica-mechanical (adhesion, impact strength, elasticity of the film during bending), decorative (change in gloss, color, dirt retention, chalking) and protective (cracking, peeling, weathering, bubble formation, corrosion of metaln, wrinkling, dissolution) properties of a two-layer coating, as well as its resistance to water, gasoline, mineral oil and temperature.
\end{abstract}

\section{References}

[1] S.A. Drinberg, E.F. Itsko. Solvents for paints and varnishes: A reference guide. Leningrade: Chemistry. 1986. 208p. (russian)

[2] M.Kh. Karapetyants, S.I. Drakin. General and inorganic chemistry. Moscow: Higher. shk. 1981. 632p. (russian)

[3] I.L. Rosenfeld, F.I. Rubinstein. Anti-corrosion primers and inhibited paints. Moscow: Chemistry. 1980. 200p. (russian)

[4] A.V. Pavlov, Yu.I. Merkulova, A.D. Zelenskaya, V.G. Zheleznyak. Wear resistance of paints and varnishes. Lakokrasochnyye materialy i ikh primeneniye. 2018. No.1-2. P.40-43. (russian)

[5] A.M. Kontorov, and A.Yu. Glushchenko. Oligomethylphenylsiloxanes and methylphenylsiloxane resins: preparation, use and compositions. Butlerov Communications. 2020. Vol.62. No.6. P.7-19. DOI: 10.37952/ROI-jbc-01/20-62-6-7

[6] S.V. Chuppina. Modification of organosilicate compositions with polyurethane. Butlerov Communications. 2006. Vol.9. No.5. P.38-49. (russian)

[7] GOST 8420-74. Paints and varnishes. Methods for determining the conditional viscosity. (russian)

[8] GOST 15140-78. Paints and varnishes. Methods for determining adhesion. (russian)

[9] GOST 6806-73. Paints and varnishes. Methods for determining the elasticity of the film in bending. (russian)

[10] GOST 4765-73. Paints and varnishes. Impact strength determination method. (russian)

[11] GOST 9.072-2017. Unified system of protection against corrosion and aging (ESZKS). Paint coatings. Terms and Definitions. (russian)

[12] GOST 9.407-2015. Unified system of protection against corrosion and aging (ESZKS). Paint coatings. Appearance assessment method. (russian) 
[13] GOST R 51691-2008. Paints and varnishes. Enamels. General technical conditions. (russian)

[14] GOST 19007-73. Paints and varnishes. Method for determining the time and degree of drying (with Amendments No. 1,2). (russian)

[15] GOST 8784-75. Paints and varnishes. Methods for determining hiding power. (russian) 